\title{
Union collusion and intra-industry trade
}

\author{
Odd Rune Straume \\ Department of Economics, University of Bergen, Fosswinckels gate 6, N-5007 Bergen, Norway
}

Received 28 June 1999; received in revised form 23 February 2000; accepted 26 February 2000

\begin{abstract}
This paper analyses the scope for collusive behaviour within the context of an international duopoly supergame in which both firms and monopoly labour unions interact strategically. We find that the presence of unions, implying an endogenisation of production costs, dramatically alters the incentives for inter-firm collusion. There are, however, strong incentives for the unions to collude, raising the wage above the equilibrium level of the one-shot game. We propose two candidates for a Nash equilibrium of the supergame, in both of which the unions collude. The main result of the paper is that the presence of unions could actually promote intra-industry trade as an equilibrium outcome of the infinitely repeated game. (C) 2002 Elsevier Science B.V. All rights reserved.
\end{abstract}

JEL classification: F12; F16; J51; L13

Keywords: Collusion; Intra-industry trade; Labour unions

\section{Introduction}

Theories of collusion deal almost exclusively with a game context in which firms are the only players. However, in many markets the strategic interactions involve other types of players, who could have a direct influence on the firms' payoffs. The prime example is labour unions.

The implications for collusive behaviour in markets with labour unions are perhaps most powerful in the context of international trade. In this paper we

E-mail address: odd.straume@econ.uib.no (O.R. Straume). 
attempt to analyse possible effects of labour unions on trade patterns, wages and welfare in the setting of an international duopoly supergame, using a standard model of reciprocal dumping.

The duopoly model of reciprocal dumping was first developed by Brander (1981), and elaborated on by Brander and Krugman (1983). The main idea is that imperfect product market competition gives rise to intra-industry trade, even when there are transportation costs associated with trade.

Extensions to the reciprocal dumping model have included both firm collusion and labour unions, but not simultaneously. Pinto (1986) and Fung (1991) show that collusion in an international duopoly, implying no trade, is a strong equilibrium of the supergame. Lommerud and Sørgard (1998) extend the analysis to find that a reduction of trade costs will have opposite effects on the stability of a collusive agreement, depending on whether conjectures are Cournot or Bertrand. In a more general analysis Anderson et al. (1989) find that with oligopolistic autarkic industries operating in two different countries, firms in at least one of the countries would lose from opening up to free trade.

Brander and Spencer (1988) and Mezzetti and Dinopoulos (1991) analyse an international duopoly where the labour market in one of the countries is unionised, while Naylor $(1998,1999)$ considers the case where the labour markets in both countries are unionised. One main result of Naylor (1999) is that the presence of unions makes intra-industry trade less likely.

The prime purpose of this paper is to analyse the scope for collusive behaviour when labour markets are unionised. We use the basic analytical framework of Naylor $(1998,1999)$ to analyse possible outcomes in a repeated game version of the model. It turns out that introducing labour unions to the model dramatically changes the scope for firm collusion. There are, however, considerable incentives for labour unions to act collusively, by increasing the wage above the noncooperative equilibrium level of the one-shot game.

After proposing two candidates for a Nash equilibrium of the supergame, in both of which the unions collude, we also want to analyse the effects of trade liberalisation on equilibrium wages, provided that union collusion is sustained. The effects of trade liberalisation in the presence of both product and labour market imperfections have previously been extensively analysed (see e.g. Huizinga, 1993; Driffill and van der Ploeg, 1993, 1995; Sørensen, 1994; Naylor, 1998), but not in a repeated game setting.

Finally, we want to consider the welfare implications of unionisation when the effects of strategic interactions between unions and firms are taken into consideration. By identifying a pro-competitive effect of labour unions, we are able to show that unionisation could possibly be welfare improving.

The main result of the paper is that for sufficiently low levels of trade costs union collusion implies intra-industry trade, and thus the presence of labour unions could actually promote trade. In relation to Fung (1991), who shows that collusive intra-industry trade is possible only when products are differentiated, this paper 
suggests that the presence of unions makes collusive trade possible even in the homogeneous good case.

Although Naylor (1999) briefly touches on the subject, the closest references to the idea of union collusion as presented in this paper are perhaps Driffill and van der Ploeg (1993, 1995), who in a somewhat different analytical framework find that trade liberalisation increases the incentives for national unions to cooperate internationally. Recently, labour unions throughout Europe have expressed an interest in obtaining a more coordinated wage bargaining process within the internal market of the EU. This could be seen as an attempt to regain some of the union power which has been lost due to trade liberalisation. In this paper we do not explicitly consider a formal cooperation between unions across borders. Instead we focus on the possibilities of obtaining some kind of collusive agreement.

The rest of the paper is organised as follows. In Section 2 the analytical framework is presented. In Section 3 the incentives for firm collusion in the presence of monopoly unions are the two-stage game is analysed, while Section 4 analyses the incentives for the unions to form a collusive agreement. Section 5 examines the effects of trade liberalisation on wages, provided that a collusive equilibrium is sustained. In Section 6 the sustainability of union collusion is analysed, while Section 7 discusses the welfare aspects of unionisation within the model. Section 8 closes the paper.

The quite common practice of adopting simple concrete functional forms in oligopoly models is also used in this paper, in the belief that the computational conveniences outweigh the loss of generality.

\section{The basic model}

We consider an international duopoly with firms in two identical countries producing a homogeneous commodity. Firm 1 is located in country $A$, whereas firm 2 is located in country $B$. If a firm is exporting, it has to pay a constant cost $t$ per unit of the commodity exported. This cost can be interpreted as transportation costs, or more general trade costs, including tariffs.

Like Brander and Krugman (1983), and most models of intra-industry trade in identical commodities, we adopt the segmented market hypothesis. This means that each firm regards each country as a separate market, and chooses the profit-maximising quantity for each market separately. The assumption of segmented markets, when combined with the assumption of constant marginal costs, implies that the price of the good in either market is solely a function of the total amount of the good available in that country.

Labour is the only factor of production and each worker supplies one unit of labour to the firm. We adopt a very simple linear production function, given by: 


$$
Q_{i}=L_{i}
$$

where $Q_{i}$ is total quantity produced by firm $i$, and $L_{i}$ is the total amount of labour employed by firm $i$. In this case, output and employment are equivalent. Production by firm $i$ for consumption in country $k$ will be denoted by $L_{i}^{k}$.

Following Naylor (1998), we assume that wages are determined by monopoly unions, which seek to maximise labour rents. As pointed out by Dowrick (1989), this can be viewed as a limiting case of the wage-bargaining union, where the union has all the bargaining power and attaches equal weights to wages and employment.

The timing of the two-stage game is as follows. In stage 1, each union chooses its rent-maximising (Bertrand) wage, $w$, taking as given the wage set by the other union. In stage 2, each firm chooses its (Cournot) output levels for each market, taking as given the output decisions of the other firm and the wage set by its own union.

The demand for the commodity is assumed to be linear, and identical in the two countries. The inverse demand function describing the total demand for the commodity in country $k$ is given by:

$$
P_{k}=1-Q_{k}
$$

where $P_{k}$ is the price of the commodity in country $k$, and $Q_{k}=L_{1}^{k}+L_{2}^{k} ; k=A, B$.

We solve the game by backwards induction, concentrating first on the firms' profit maximisation problem.

\subsection{Firm behaviour}

Using (2), the profit of firm 1 is given by:

$$
\pi_{1}=\left(1-L_{1}^{A}-L_{2}^{A}-w_{1}\right) L_{1}^{A}+\left(1-L_{1}^{B}-L_{2}^{B}-w_{1}-t\right) L_{1}^{B}
$$

And similarly, the profit of firm 2 can be written as:

$$
\pi_{2}=\left(1-L_{1}^{B}-L_{2}^{B}-w_{2}\right) L_{2}^{B}+\left(1-L_{1}^{A}-L_{2}^{A}-w_{2}-t\right) L_{2}^{A}
$$

Firms maximise profits by choosing the optimal output level for each market separately. The first-order conditions for profit maximisation for firm 1 and firm 2, respectively, are given by:

$$
\begin{aligned}
& L_{1}^{A}=\frac{1}{2}\left(1-L_{2}^{A}-w_{1}\right) \\
& L_{1}^{B}=\frac{1}{2}\left(1-L_{2}^{B}-w_{1}-t\right) \\
& L_{2}^{B}=\frac{1}{2}\left(1-L_{1}^{B}-w_{2}\right)
\end{aligned}
$$




$$
L_{2}^{A}=\frac{1}{2}\left(1-L_{1}^{A}-w_{2}-t\right)
$$

The choice of whether to supply only the home market or exporting into the other market depends crucially on the trade costs and the wage levels. In principle, the outcome of the game can be classified in four different regimes: Intra-industry trade (IIT), one-way trade either way or autarky. The equilibrium outcome must be symmetric, though, and we will focus on the two symmetric regimes: IIT and autarky. ${ }^{1}$

Under the assumption that both firms choose positive output levels in both markets, i.e. IIT, we can derive the following labour demand functions from (5)-(8):

$$
\begin{aligned}
& L_{1}^{A}=\frac{1}{3}\left(1+w_{2}-2 w_{1}+t\right) \\
& L_{1}^{B}=\frac{1}{3}\left(1+w_{2}-2 w_{1}-2 t\right) \\
& L_{2}^{A}=\frac{1}{3}\left(1+w_{1}-2 w_{2}-2 t\right) \\
& L_{2}^{B}=\frac{1}{3}\left(1+w_{1}-2 w_{2}+t\right)
\end{aligned}
$$

Due to symmetry, the wage levels must be equal in equilibrium. Setting $w_{1}=$ $w_{2}=w$, the equilibrium IIT profits, $\pi_{\text {tr }}$, can be calculated as:

$$
\pi_{\mathrm{tr}}=\frac{2}{9}-\frac{4}{9} w-\frac{2}{9} t+\frac{2}{9} w^{2}+\frac{2}{9} w t+\frac{5}{9} t^{2}
$$

When there is no intra-industry trade, the firms act as monopolists in their respective home markets. Thus, the labour demand functions in the autarky regime are derived by solving (5)-(8) when $L_{1}^{B}=L_{2}^{A}=0$. This gives:

$$
\begin{aligned}
L_{1}^{A} & =\frac{1}{2}\left(1-w_{1}\right) \\
L_{2}^{B} & =\frac{1}{2}\left(1-w_{2}\right)
\end{aligned}
$$

Again setting $w_{1}=w_{2}=w$, the equilibrium autarky profits, $\pi_{\mathrm{au}}$, are given by:

$$
\pi_{\mathrm{au}}=\frac{1}{4}(1-w)^{2}
$$

\footnotetext{
${ }^{1}$ Naylor (1999) shows that all equilibria in pure strategies must be symmetric.
} 


\subsection{Union behaviour}

Unions are assumed to maximise labour rents. As a simplifying assumption the reservation wage is normalised to zero. Hence, the utility of union $i$ is given by: ${ }^{2}$

$$
U_{i}=w_{i}\left(L_{i}^{A}+L_{i}^{B}\right)
$$

A key feature of the model is that the unions, by having the advantage of being first-movers, can dictate the outcome of the game in terms of trade regimes. The firms would find it profitable to export only if the sum of production and trade costs is small enough for intra-industry trade to yield a positive profit contribution. Hence the unions can induce an autarky solution by setting a wage that is too high for trade to be profitable. Whether the unions will choose a high-wage or a low-wage strategy will of course depend on the union utility obtained by choosing a given strategy. In the two-stage game the optimal strategy is solely dependent on the trade costs, $t$.

In an IIT equilibrium, the unions maximise labour rents by setting wages according to the labour demand given by (9)-(12). Setting $w_{1}=w_{2}=w$ and inserting (9)-(12) in (17), the equilibrium IIT utility, $U_{\mathrm{tr}}$, is given by:

$$
U_{\mathrm{tr}}=\frac{1}{3}(2-2 w-t) w
$$

It can be easily shown that the equilibrium IIT wage in the one-shot game, $w_{\text {tr }}$, is given by:

$$
w_{\mathrm{tr}}=\frac{1}{3}-\frac{1}{6} t
$$

If, on the other hand, both unions adopt a high-wage strategy, and thereby prevent the firms from exporting, the model collapses into two completely separate (but symmetric) games, and there is no longer any interdependence between the wage levels in the two countries. In this case both unions set wages according to the labour demand given by (14)-(15). Inserting (14)-(15) into (17) and setting $w_{1}=w_{2}=w$ yields the autarky utility:

$$
U_{\mathrm{au}}=\frac{1}{2}(1-w) w
$$

The autarky wage, $w_{\mathrm{au}}$, obtained by maximisation of (20), is easily calculated as:

$$
w_{\mathrm{au}}=\frac{1}{2}
$$

A comparison of (19) and (21) confirms that the wage level associated with non-collusive IIT is everywhere below the wage level in an autarky equilibrium.

\footnotetext{
${ }^{2}$ A more general Stone-Geary utility function would not change the results in any essential way.
} 
With intra-industry trade the unions will be competing with each other over employment. This will cause a reduction in the wage level, compared to autarky. Thus, an important aspect of trade in this model is the erosion of union power, compared to the autarky case.

As previously mentioned, the choice of union strategies is solely dependent on the level of trade costs. It can be shown that the prohibitive level of trade costs below which IIT will be supported in a pure strategy Nash equilibrium is given by: ${ }^{3}$

$$
t^{*}=\frac{8}{13+9 \sqrt{2}} \approx 0.31
$$

It should be noted that in the absence of unions, which in this model implies zero production costs, the prohibitive level of trade costs is given by $t=\frac{1}{2}$. Hence, the presence of unions makes IIT a less likely outcome of the one-shot game.

\section{Firm collusion}

The major insight from the original Brander-Krugman model of reciprocal dumping is that oligopolistic rivalry between firms can, even in the presence of trade costs, lead to trade in identical products. Thus, the model establishes imperfect competition as an independent cause of international trade. However, it has been pointed out that in a repeated game the firms have strong incentives to reach a collusive agreement that implies autarky (see e.g. Pinto, 1986; Fung, 1991; Lommerud and Sørgard, 1998).

The Prisoners' Dilemma characteristics of the model can be restated in the following proposition:

Proposition 1. For a given wage $w$, the IIT equilibrium is Pareto dominated by the autarky equilibrium for the firms.

A comparison of (13) and (16) reveals that $\pi_{\mathrm{au}}(w)>\pi_{\mathrm{tr}}(w)$ if $t<\frac{1}{2}-\frac{1}{2} w$. Thus, for any combination of $w$ and $t$ where intra-industry trade is unilaterally profitable, the firms would jointly benefit from an autarky equilibrium. An obvious interpretation of Proposition 1 is that in the absence of unions the incentives for firm collusion are strong.

However, introducing unions to the model of reciprocal dumping implies that production costs are endogenised. Intra-industry trade implicitly leads to competition between unions over employment, and causes a reduction in the wage level compared to the autarky case. A key feature of the model is that by engaging in

\footnotetext{
${ }^{3}$ See Naylor (1999) for a thorough analysis of union strategies within this model.

${ }^{4}$ This point is also made by Naylor (1999).
} 
IIT the firms are able to enjoy the benefits of both international price discrimination and an erosion of union power. So from the viewpoint of the firm trade serves two different purposes, and the presence of unions makes IIT a more attractive option compared to autarky.

The presence of unions dramatically alters the scope for firm collusion. The equilibrium IIT wage, $w_{\text {tr }}$, and the equilibrium autarky wage, $w_{\text {au }}$, are given by (19) and (21), respectively. By inserting $w=w_{\text {tr }}$ in (13) and $w=w_{\text {au }}$ in (16) we find that:

$$
\pi_{\mathrm{tr}}\left(w_{\mathrm{tr}}\right)>\pi_{\mathrm{au}}\left(w_{\mathrm{au}}\right) \quad \forall t
$$

This establishes Proposition 2:

Proposition 2. In the presence of unions, acting non-collusively, the autarky equilibrium is Pareto dominated by the IIT equilibrium for the firms.

When the unions act non-collusively, engaging in wage-cutting competition, the firms have no incentives to implement an autarky solution by forming a collusive agreement. Engaging in IIT has two opposite effects on profits, compared to autarky, and in a non-collusive IIT equilibrium the benefits to the firm from inter-union competition, in the form of lower wages, outweigh the costs from inter-firm competition, in the form of lower prices.

The above analysis suggests that the presence of unions would actually promote IIT as an equilibrium outcome in a repeated game. The crucial question, however, is why the unions would choose the Bertrand wage in a repeated game? It would be reasonable to expect that the unions have incentives to somehow eliminate, or at least diminish, the (inter-union) competitive nature of the IIT equilibrium given by (19).

\section{Union collusion}

In this model union collusion means that both unions form an agreement to set a wage in excess of the Bertrand level given by (19). In this section of the paper we want to examine under which conditions this could be part of a Nash equilibrium in the supergame. First of all it should be pointed out that the equilibrium of the one-shot game is also one of several equilibria in the infinitely repeated game, but perhaps not the most interesting one. We will therefore proceed by looking for a Nash equilibrium in which the unions collude on a high wage.

In a repeated two-stage game with four players the set of possible strategy combinations is obviously very large. Hence, we have to make some simplifying assumptions in order to make the analysis tractable. We will do so by excluding equilibria which imply solutions off the labour demand curves. An implication of this is that the possibility of firm-union collusion is excluded. Espinosa and Rhee 
(1989) show that when the repeated nature of the wage bargaining process is considered the equilibria would typically lie somewhere in between the monopoly union solution and the efficient bargaining solution, depending on the players' discount factors. However, in a model with four players we expect collusion to be either inter-firm or inter-union.

We consider the case of efficient union collusion, whereby the unions set the collusive wage $w_{\mathrm{c}}(t)$ that maximises joint union utility. In a symmetric model this seems to be a plausible collusive strategy. For the time being we will assume that the unions are sufficiently patient, so that any $w_{\mathrm{c}}(t) \in\left\langle w_{\mathrm{tr}}(t), w_{\mathrm{au}}\right]$ can be realised in a subgame-perfect Nash equilibrium. ${ }^{6}$ In Section 6 we will return with a full specification of the strategies needed to support $w_{\mathrm{c}}(t)$ as a subgame-perfect equilibrium outcome of the supergame.

Whether joint union utility is maximised by inducing an autarky or an IIT solution depends on the magnitude of trade costs. Technically, we can construct the unions' problem as a choice between maximising equilibrium IIT utility or equilibrium autarky utility, as given by (18) and (20), respectively, subject to a relevant constraint concerning firm behaviour.

We will initially make the simplest possible assumption about firm behaviour, namely that the firms act as Cournot players in every period of the game. In this case the unions are free to choose the unconstrained collusive wage, $w_{\mathrm{c}}^{*}(t)$.

In maximising equilibrium autarky utility the choice of $w_{\mathrm{c}}(t)$ is restricted by the condition that the wage must be high enough for export production not to be profitable for the firms. In this case the optimal collusive wage is given by:

$$
w_{\mathrm{c}}=\arg \max \frac{1}{2}\left(1-w_{\mathrm{c}}\right) w_{\mathrm{c}} \quad \text { s.t. } \quad w_{\mathrm{c}} \geqslant 1-2 t
$$

On the other hand, in maximising equilibrium IIT utility the optimal choice of $w_{\mathrm{c}}(t)$ is given by:

$$
w_{\mathrm{c}}=\arg \max \frac{1}{3}\left(2-2 w_{\mathrm{c}}-t\right) w_{\mathrm{c}} \quad \text { s.t. } \quad w_{\mathrm{c}}<1-2 t
$$

The unconstrained collusive wage, $w_{\mathrm{c}}^{*}(t)$, is a piecewise linear function of $t$ :

$$
w_{\mathrm{c}}^{*}(t)=\left\{\begin{array}{llrl}
\frac{1}{2} & \text { if } & t>2-\sqrt{3} & \approx 0.27 \\
\frac{1}{2}-\frac{1}{4} t & \text { if } & t \leqslant 2-\sqrt{3} \approx 0.27
\end{array}\right.
$$

\footnotetext{
${ }^{5}$ Asymmetric solutions, on the other hand, would imply some kind of utility transfer, which is somewhat difficult to imagine how should be implemented.

${ }^{6}$ This corresponds to saying that the discount factor is sufficiently close to 1 . In that case the Folk Theorem (Friedman, 1971) guarantees the existence of a subgame-perfect Nash equilibrium in which the unions choose the wage $w_{\mathrm{c}}(t)$.

${ }^{7}$ This constraint is necessary to ensure that an autarky solution is indeed induced.
} 
The choice of an optimal collusive wage could be described as a choice between a high wage/low employment combination (autarky) versus a low wage/high employment combination (IIT). The unions will benefit from the employment effect of inter-firm competition, but this employment effect can only be obtained at a certain cost, namely by accepting a wage below $w_{\text {au }}$. When trade costs are high the unions would have to set a relatively low wage in order to implement an IIT solution. From (22) we see that if $t \geqslant 2-\sqrt{3}$ it is too costly for the unions to obtain the benefits from inter-firm competition, and joint union utility is maximised by setting the autarky wage, thus inducing an autarky solution.

As $t$ decreases the employment benefits from IIT can be obtained at a decreasing cost, and if $t \leqslant 2-\sqrt{3}$ the optimal collusive strategy is a low-wage strategy, implying IIT.

The assumption that the firms always act as Cournot players in the supergame is obviously quite strong. We will therefore go on to relax this assumption by allowing for the possibility of firm collusion. We assume that if the firms collude, they do so by retreating from the export markets and acting as monopolists in their respective home markets. This is the kind of collusive behaviour that, for a given wage level, maximises total industry profits. Furthermore, it is also the most easily observable collusive strategy.

The possibility of firm collusion can be modelled as a constraint on the unions' choice of collusive wage. If the firms collude as a response to a wage $w<w_{\text {au }}$ the unions will react to this by raising the wage to $w_{\text {au }}$. This is the optimal union reaction, unilaterally and bilaterally, to firm collusion. Thus, firm collusion will be an option only if the autarky equilibrium yields a higher payoff to the firms than the IIT equilibrium implied by a suggested wage $w$, i.e. $\pi_{\mathrm{au}}\left(w_{\mathrm{au}}\right)>\pi_{\mathrm{tr}}(w)$. If the unions want to induce an IIT solution to the game they will have to set a wage that is sufficiently low in order to eliminate the incentives for firm collusion.

When the possibility of firm collusion is introduced, it affects collusive wage setting in that the wage that maximises equilibrium IIT utility is constrained in the following way:

$$
w_{\mathrm{c}}=\arg \max \frac{1}{3}\left(2-2 w_{\mathrm{c}}-t\right) w_{\mathrm{c}} \quad \text { s.t. } \quad \pi_{\mathrm{tr}}\left(w_{\mathrm{c}}\right) \geqslant \pi_{\mathrm{au}}\left(w_{\mathrm{au}}\right)
$$

where $\pi_{\mathrm{tr}}$ and $\pi_{\mathrm{au}}$ are given by (13) and (16), respectively.

The constrained collusive wage, $\hat{w}_{\mathrm{c}}(t)$, is then given by:

$$
\hat{w}_{\mathrm{c}}(t)= \begin{cases}\frac{1}{2} & \text { if } t>2-\sqrt{3} \\ \frac{1}{2}-\frac{1}{4} t & \text { if } \quad \frac{2}{37}+\frac{3}{74} \sqrt{10} \leqslant t \leqslant 2-\sqrt{3} \\ 1-\frac{1}{2} t-\frac{3}{8} \sqrt{2-16 t^{2}} & \text { if } \quad t<\frac{2}{37}+\frac{3}{74} \sqrt{10}\end{cases}
$$

\footnotetext{
${ }^{8}$ This assumption is also used by Fung (1991) and Lommerud and Sørgard (2001).
} 
If $t \geqslant \frac{2}{37}+\frac{3}{74} \sqrt{10} \approx 0.18$ the optimal wage is unconstrained, and $\hat{w}_{\mathrm{c}}=w_{\mathrm{c}}^{*}$. If $t<\frac{2}{37}+\frac{3}{74} \sqrt{10}$ the constraint is binding and the optimal wage is a nonlinear function of $t$. In this region of trade costs the global joint utility maximum is unobtainable since it implies setting a wage so high that it would induce the firms to collude. Thus, the optimal collusive strategy for the unions implies setting a wage that is just low enough for the corresponding IIT equilibrium to Paretodominate the autarky equilibrium from the viewpoint of the firms.

The properties of $w_{\mathrm{c}}^{*}(t)$ and $\hat{w}_{\mathrm{c}}(t)$ are further discussed in the next section. It is worth noticing, though, that since $w_{\mathrm{c}}^{*}$ and $\hat{w}_{\mathrm{c}}$ are everywhere above $w_{\mathrm{tr}}$, collusive IIT implies smaller trade volumes than non-collusive IIT.

When comparing (22) and (23) it is also important to note that the prohibitive level of trade costs, below which efficient union collusion implies IIT, is not dependent upon whether or not collusive wage setting is constrained by the possibility of firm collusion. In both cases intra-industry trade will be the outcome if $t$ is below $2-\sqrt{3}$.

Having shown that union collusion implies IIT if $t \leqslant 2-\sqrt{3}$, we are now ready to state the main proposition of the paper:

Proposition 3. The presence of labour unions makes IIT a more likely outcome of an infinitely repeated game.

In a one-shot game the presence of unions makes IIT less likely, by lowering the prohibitive level of trade $\operatorname{costs}^{10}$ (Naylor, 1999). However, in a repeated game this result is reversed. In the absence of unions, autarky, due to firm collusion, is a likely outcome of the repeated game (by Proposition 1). The introduction of non-cooperative unions, however, means that the incentives for firm collusion disappear (by Proposition 2). Instead, the unions themselves have rather strong incentives to form a collusive agreement, raising the equilibrium wage above the Bertrand level. But for sufficiently low levels of trade costs, $t \leqslant 2-\sqrt{3}$, the optimal collusive strategy implies intra-industry trade. Thus, the presence of unions makes IIT a more likely outcome of the repeated game.

\section{Trade liberalisation}

In this section we want to examine the effects of trade liberalisation, interpreted as a reduction of $t$, on equilibrium wages, assuming that union collusion is

\footnotetext{
${ }^{9}$ For simplicity we assume that $\pi_{\mathrm{tr}}\left(w_{\mathrm{c}}\right)=\pi_{\mathrm{au}}\left(w_{\mathrm{au}}\right)$ is a sufficient condition for firm collusion not to occur.

${ }^{10}$ In the absence of unions the prohibitive level of trade costs is given by $t=0.5$, whereas in the presence of monopoly unions IIT will be the outcome of the two-stage game if $t<0.31$.
} 
sustained. The implications of union collusion are heavily dependent on the magnitude of trade costs, and we will therefore introduce the following three regions of $t$ :

(i) Region I: $t>2-\sqrt{3}, w_{\mathrm{c}}^{*}(t)=\hat{w}_{\mathrm{c}}(t)=w_{\mathrm{au}}$ and there is no trade in equilibrium.

(ii) Region II: $\frac{2}{37}+\frac{3}{74} \sqrt{10} \leqslant t \leqslant 2-\sqrt{3}, w_{\mathrm{c}}^{*}(t)=\hat{w}_{\mathrm{c}}(t)$ and there is intraindustry trade in equilibrium.

(iii) Region III: $t<\frac{2}{37}+\frac{3}{74} \sqrt{10}, w_{\mathrm{c}}^{*}(t)>\hat{w}_{\mathrm{c}}(t)$ and there is intra-industry trade in equilibrium.

When we consider the effect of trade liberalisation on wages it is important to distinguish between the change in equilibrium wages when switching from autarky to IIT, and the wage effect of a reduction in $t$ within the context of an IIT regime.

We start by considering the case of IIT, i.e. Regions II and III. For comparative purposes the equilibrium IIT wage of the one-shot game is restated:

$$
w_{\mathrm{tr}}=\frac{1}{3}-\frac{1}{6} t
$$

From (19) the effect of trade liberalisation follows directly:

$$
\frac{\mathrm{d} w_{\mathrm{tr}}}{\mathrm{d} t}=-\frac{1}{6}
$$

Hence, in a one-shot game a marginal reduction of trade costs gives rise to an increase in wages. This is the main result of Naylor (1998), and it is intuitively explained by the fact that a marginal reduction in $t$ increases the total demand for labour in each country. Since the unions maximise labour rents they will respond by setting a higher wage.

The effect of trade liberalisation on the collusive wage in Region II follows from (22):

$$
\frac{\mathrm{d} w_{\mathrm{c}}^{*}(t)}{\mathrm{d} t}=-\frac{1}{4}
$$

When $0.18 \leqslant t \leqslant 0.27$ a reduction in $t$ yields qualitatively the same result with regard to wages whether the equilibrium is collusive or not, but comparing with (19) we see that the wage increase due to trade liberalisation is larger under collusive IIT. By coordinating their wage demands the unions are able to eliminate the competitive nature of non-collusive wage setting. Consequently, they will respond to an increase in labour demand by raising the wage even more, compared to the non-collusive equilibrium.

In Region III, trade liberalisation has different implications for equilibrium wages depending on whether or not the collusive wage is constrained. If collusive wage setting is not constrained by firm collusive incentives the effect of trade 
liberalisation on wages is given by (22). An interesting feature of the unconstrained collusive wage is that:

$$
w_{\mathrm{c}}^{*}(0)=\frac{1}{2}
$$

If trade is costless for the firms, the unconstrained collusive wage is equal to the autarky wage. In the non-collusive equilibrium, the fact that $w_{\mathrm{tr}}(0)<w_{\mathrm{au}}$ is solely due to wage-cutting competition between unions. If the unions are able to eliminate this competition by colluding, they will set the autarky wage when trade costs are zero.

However, if the unions collude on $\hat{w}_{\mathrm{c}}(t)$ the effect of a marginal reduction in $t$ follows from (23):

$$
\frac{\mathrm{d} \hat{w}_{\mathrm{c}}(t)}{\mathrm{d} t}=-\frac{1}{2}\left(\frac{\sqrt{2-16 t^{2}}-12 t}{\sqrt{2-16 t^{2}}}\right)
$$

A closer inspection of (26) reveals that:

$$
\frac{\mathrm{d} \hat{w}_{\mathrm{c}}(t)}{\mathrm{d} t}>(<) 0 \quad \text { if } \quad t>(<) \frac{1}{20} \sqrt{5}
$$

Thus, if the trade costs are within the interval $\left(\frac{1}{20} \sqrt{5}, \frac{2}{37}+\frac{3}{74} \sqrt{10}\right)$, or approximately $0.11<t<0.18$, the equilibrium wage would actually fall as a response to trade liberalisation.

The intuition behind this result is found by looking at the effect of trade liberalisation on equilibrium trade profits. From (13) we can calculate this effect as:

$$
\frac{\mathrm{d} \pi_{\mathrm{tr}}}{\mathrm{d} t}=-\frac{2}{9}+\frac{2}{9} w+\frac{10}{9} t
$$

For a given wage $w$, a marginal reduction of trade costs has two opposite effects on equilibrium trade profits. On one hand, trade liberalisation causes prices to fall due to increased product market competition, thereby reducing profits. On the other hand, trade liberalisation has a direct cost-reducing (positive) effect on profits. From (27) we see that when $t$ is initially relatively high, the former effect is dominating, whereas the opposite is true for relatively low levels of $t$.

When $t<0.18, \hat{w}_{\mathrm{c}}$ is constrained by the condition that equilibrium trade profits must be at least as high as equilibrium autarky profits. Suppose that $t$ is initially given by $0.11<t<0.18$. If $t$ falls, the effect of increased product market competition is larger than the cost-reducing effect on equilibrium profits in this particular interval of trade costs. Thus, the unions have to compensate for this by reducing the collusive wage in order to sustain the desired level of firm profits in the IIT equilibrium.

So far we have considered the effect of trade liberalisation on wages in the context of an IIT equilibrium. However, the most dramatic change in wages occurs 
when the equilibrium switches from autarky to IIT. In the case of a non-collusive equilibrium the lowest equilibrium wage occurs at the prohibitive level of trade costs, $t^{*}=\frac{8}{13+9 \sqrt{2}}$. From (19) we find this wage to be:

$$
w_{\text {tr }}\left(t^{*}\right)=\frac{3(1+\sqrt{2})}{13+9 \sqrt{2}} \approx 0.28
$$

If the players do not collude, intra-industry trade at the prohibitive level of trade costs implies that wages drop by almost $44 \%$, compared to the autarky equilibrium. ${ }^{11}$

In the case of union collusion the switch from autarky to IIT occurs at $t^{* *}=2-\sqrt{3}$. From (22) it follows that:

$$
w_{\mathrm{c}}^{*}\left(t^{* *}\right)=\frac{\sqrt{3}}{4} \approx 0.43
$$

In this case, the switch from autarky to IIT implies that wages drop by about $13 \%$.

In Fig. 1, the wage outcomes of the different equilibria are illustrated. The collusive outcomes are given by the thick curves, while the thin curve illustrates the non-collusive outcomes. The thick gray curve in Region III corresponds to the case of constrained union collusion.

The effects of trade liberalisation on equilibrium wages under intra-industry trade can be summarised in the following proposition:

Proposition 4. From an initial situation of IIT, trade liberalisation will cause

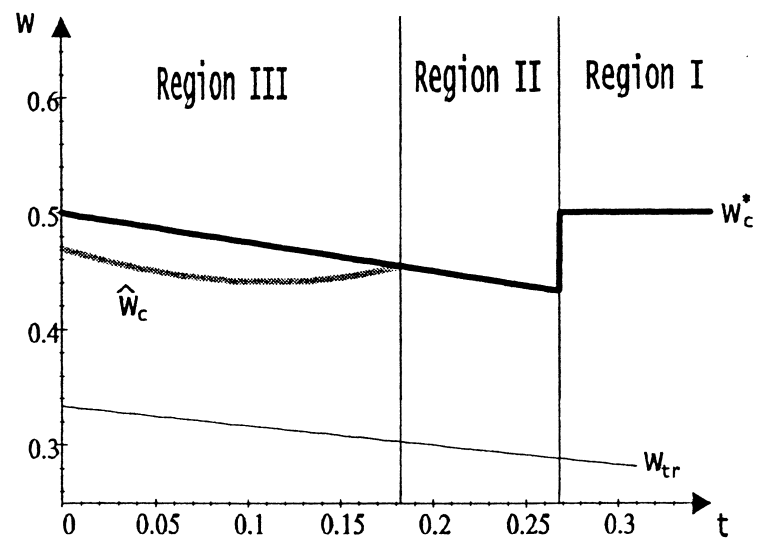

Fig. 1. Equilibrium wage outcomes.

\footnotetext{
${ }^{11}$ It should be noted that there is a small interval $t \in[0.31,0.35]$ where an equilibrium in pure strategies does not exist in the one-shot game. See Naylor (1999) for further details.
} 
wages to increase under unconstrained union collusion, and the wage increase will be larger compared to the non-collusive equilibrium. If union collusion is constrained, trade liberalisation will cause wages to decrease if $0.11<t<0.18$.

\section{Sustainability of union collusion}

Either union will always be able to capture an instant utility gain by unilaterally deviating from the collusive strategy. Deviation implies lowering the wage, inducing the home firm to act more aggressively in the foreign market by increasing exports. Thus, collusion can only be sustained if it is backed by credible threats, making the discounted punishment greater than the one-period gain from deviation.

We assume that the unions play a trigger strategy implying a permanent reversion to non-cooperative (Bertrand) wage-setting following any deviation from the collusive wage-setting. We also assume that the discount factor is equal for both unions. The strategy of the firms is simply to choose the Cournot quantities in each market in every period of the repeated game. We now want to find the critical discount factor above which the proposed strategies constitute a subgame-perfect Nash equilibrium of the infinitely repeated two-stage game.

In order to specify the relevant payoff functions we have to distinguish between the different regions of trade costs. The punishment utility, $U_{\mathrm{p}}$, is equal in all three regions, but the collusive utility, $U_{\mathrm{c}}$, and the utility from deviation, $U_{\mathrm{d}}$, will differ. Generally, the condition for the trigger strategy to constitute a subgame-perfect equilibrium in the infinitely repeated game is given by:

$$
\frac{1}{(1-\delta)} U_{\mathrm{c}} \geqslant U_{\mathrm{d}}+\frac{\delta}{(1-\delta)} U_{p}
$$

\subsection{Region I}

Inserting the relevant payoff functions into (28) yields the following critical discount factor:

$$
\delta^{*}=\frac{9}{4}\left(\frac{15-48 t+16 t^{2}}{25-52 t+22 t^{2}}\right)
$$

The sustainability of collusion in Region I is dependent on the magnitude of trade costs. The nature of this dependence can be further analysed by taking the derivative of $\delta^{*}$ with respect to $t$ :

$$
\frac{\mathrm{d} \delta^{*}}{\mathrm{~d} t}=\frac{-63\left(15-5 t-8 t^{2}\right)}{\left(25-52 t+22 t^{2}\right)^{2}}
$$

We find that $\mathrm{d} \delta^{*} / \mathrm{d} t<0$ for the relevant levels of $t$. Hence, a reduction of trade 
costs makes collusion, which in this case means autarky, increasingly difficult to sustain. The reason is that a reduction of trade costs makes deviation more attractive, while the punishment is less severe. In general, as $t$ falls, IIT is an increasingly attractive option to the unions.

The critical discount factor reaches its highest level at the lower boundary of Region I. Inserting $t=2-\sqrt{3}$ into (29) yields $\delta^{*} \approx 0.59$.

\subsection{Region II}

Again, inserting the relevant payoff functions into (28) yields a critical discount factor:

$$
\delta^{*}=\frac{9}{17}
$$

We see that, somewhat surprisingly, the sustainability of union collusion is unaffected by the level of trade costs. A marginal reduction of $t$ will lead to a proportionate increase in both the discounted utility of sustaining collusion and the discounted utility from deviating, thus keeping the critical discount factor at the same level.

\subsection{Region III}

If the optimal collusive strategy is constrained by firm-collusive incentives, the critical discount factor above which union collusion is sustained in Region III is given by:

$$
\delta^{*}=\frac{9\left(209-128 t+72(t-2) \sqrt{2-16 t^{2}}-616 t^{2}\right)}{721-640 t+216(t-2) \sqrt{2-16 t^{2}}-488 t^{2}}
$$

Since $\hat{w}_{\mathrm{c}}<w_{\mathrm{c}}^{*}$ in Region III we would expect the critical discount factor to be smaller when union collusion is constrained, and this is indeed the case. A closer inspection of (31) also reveals that:

$$
\frac{\mathrm{d} \delta^{*}}{\mathrm{~d} t}>(<) 0 \quad \text { if } \quad t>(<) \frac{1}{16}
$$

Hence, when trade costs are given by $\frac{1}{16}<t<\frac{2}{37}+\frac{3}{74} \sqrt{10}$ trade liberalisation will increase the sustainability of collusion.

Although $\mathrm{d} \delta * / \mathrm{d} t<0$ when $t<\frac{1}{16}$, the critical discount factor in Region III never exceeds that of Region II.

The simplistic nature of the trigger strategy makes it an appealing choice for our purposes. It should be noted, though, that a permanent reversion to the Nash equilibrium of the one-shot game is not the optimal form of punishment (Abreu, 1986), and in any case, it is hardly able to capture the full complexities of dynamic 
interactions. Nevertheless, it serves as a useful illustration of the feasibility of an international collusive agreement between labour unions to be sustained.

\section{Welfare}

The main insight from this paper is that the presence of unions will alter the scope for firm collusion, and this could potentially have strong implications for the welfare aspects of labour unions. According to conventional wisdom unionisation is welfare detrimental, since it causes a labour market distortion that results in under-employment. However, when taking into consideration the effects of unions on the strategic behaviour of firms, the welfare implications are not so clear-cut.

In analysing the welfare effects of unionisation we will introduce a more general union utility function. Assume that union $i$ maximises the following Stone-Geary utility function: ${ }^{12}$

$$
U_{i}=\left(w_{i}-\bar{w}\right)^{\theta}\left(L_{i}^{A}+L_{i}^{B}\right)^{(1-\theta)}
$$

where the parameter $\theta$ captures the relative importance of wages to the union. ${ }^{13}$ As before, the competitive wage, $\bar{w}$, will be normalised to zero.

The appropriate measure of welfare consists of three parts; consumers' surplus, firm profits and union utility. ${ }^{14}$ Unionisation implies that the unions capture some of the firms' rents. Since the utility function specified in (32) does not measure union utility in monetary terms, it is not trivial to make welfare comparisons. However, we choose to use the wage bill as a measure of union utility in the social welfare function. This implies that, from a social point of view, the division of rents between firm and union is irrelevant, only the size of total rents matter. Social welfare in country $k$ can then be defined as:

$$
W_{k}=\frac{1}{2}\left(L_{1}^{k}+L_{2}^{k}\right)^{2}+w_{i}\left(L_{i}^{A}+L_{i}^{B}\right)+\pi_{i} \quad(k, i)=(A, 1),(B, 2)
$$

As a benchmark, the Nash equilibrium when labour markets are competitive is assumed to be collusive, implying no trade. In this case each firm produces the monopoly quantity which, at $\bar{w}=0$, is given by:

$$
L_{\mathrm{au}}=\frac{1}{2}
$$

\footnotetext{
${ }^{12}$ Note that the adoption of a Stone-Geary utility function does not violate Proposition 2, which is essential for the argument about the pro-competitive effect of labour unions, unless the unions are extremely employment oriented.

${ }^{13} \mathrm{We}$ assume that $\theta$ is equal for both unions.

${ }^{14}$ If $t$ is interpreted as a tariff, IIT yields a positive government revenue that should be included in the welfare function. However, in this section of the paper trade costs will be interpreted purely as transportation costs.
} 
Profits, consumers' surplus and net social welfare in each country are easily calculated as:

$$
\begin{aligned}
& \pi_{\text {au }}=\frac{1}{4} \\
& C S_{\text {au }}=\frac{1}{8} \\
& W_{\text {au }}=\frac{3}{8}
\end{aligned}
$$

When introducing monopoly unions to the industry, Proposition 2 shows that the incentives for firm collusion are dramatically altered. By basing their wage demands on the anticipated firm behaviour the unions are inducing the firms to act more competitively.

We have previously argued that IIT is a likely outcome of the infinitely repeated two-stage game when trade costs are sufficiently low. The 'best case' equilibrium, from a welfare point of view, is the non-collusive equilibrium. In this case the unions set the wage:

$$
w_{\mathrm{tr}}=\frac{(2-t) \theta}{2(2-\theta)}
$$

and total output in each market is given by:

$$
L_{1}^{k}+L_{2}^{k}=\frac{2(1-\theta)(2-t)}{3(2-\theta)}
$$

Profits, consumers' surplus and net social welfare (including the wage bill) can then be calculated as:

$$
\begin{aligned}
& \pi_{\mathrm{tr}}=\frac{16(1-\theta)^{2}(1-t)+\left(40-44 \theta+13 \theta^{2}\right) t^{2}}{18(2-\theta)^{2}} \\
& C S_{\mathrm{tr}}=\frac{2(1-\theta)^{2}(2-t)^{2}}{9(2-\theta)^{2}} \\
& W_{\mathrm{tr}}=\frac{8(1-\theta)(4-\theta)(1-t)+\left(44-46 \theta+11 \theta^{2}\right) t^{2}}{18(2-\theta)^{2}}
\end{aligned}
$$

Considering consumers' surplus, the introduction of labour unions could have two opposite effects. On the one hand, it will cause production costs (the wage) to increase, implying a contraction of output. On the other hand, it could influence the firms' strategic behaviour, encouraging a more competitive product market performance. If the latter effect dominates, the presence of labour unions could actually increase consumers' surplus.

Whether or not the non-collusive equilibrium yields a higher market output than the benchmark equilibrium is dependent on both union preferences and trade costs. 
From (41) we see that consumers' surplus is inversely related to $\theta$ and $t$. The more employment oriented the unions are, the lower is the equilibrium wage, and the smaller is the welfare reducing effect of unionisation. Low trade costs will lead to stronger international competition, and increase the positive effects of IIT for the consumers.

A comparison of (36) and (41) reveals that the non-collusive equilibrium in the presence of unions yields a higher level of consumers' surplus compared to the benchmark equilibrium if the parameter $\theta$ is below a critical level $\theta^{*}$, given by:

$$
\theta^{*}=2\left(\frac{1-2 t}{5-4 t}\right)
$$

From (43) we see that $\theta^{*}<\frac{1}{2}$ for the relevant values of $t .^{15}$

Regarding the overall welfare effects, it is clear that the firms will always lose from unionisation. Comparing (35) and (40) we can conclude that profits will always be higher in the benchmark equilibrium. This is not very surprising, since unionisation implies a division of rents between firms and unions.

However, when we compare (37) and (42) it is apparent that total rents are lower in the non-collusive IIT equilibrium than in the benchmark equilibrium if $t>0$. Thus, when trade costs are positive, the increase in the wage bill is not able to fully compensate, in terms of social welfare, for the loss in firm profits. This is a reflection of the fact that intra-industry trade implies wasteful transportation when $t>0$. Consequently, the set of $(\theta, t)$-values that makes the prospect of welfare improving unionisation a possibility, ${ }^{16}$ is smaller than the set of $(\theta, t)$-values that could lead unionisation to increase consumers' surplus. This is illustrated in Fig. 2. The lower curve represents combinations of $\theta$ and $t$ that satisfy the equation $\pi_{\mathrm{tr}}(\theta$, $t)=\pi_{\mathrm{au}}(\theta)$, thus indicating the critical value of $\theta$ above which Proposition 2 holds. Area $A$ is the set of parameter values for which net social welfare is higher in the non-collusive equilibrium in the presence of unions than in the benchmark equilibrium. For combinations of $\theta$ and $t$ given by area $B$, on the other hand, consumers' surplus is higher while total welfare is lower under unionisation.

Although we are comparing two extreme cases, the above analysis still serves as a useful illustration of the potentially powerful welfare implications of unionisation when the effects of strategic interactions between unions and firms are taken into consideration. The essence of the analysis is summarised in the following proposition:

Proposition 5. If the unions are employment oriented, and if trade costs are

\footnotetext{
${ }^{15}$ In the following, the unions will be characterised as employment (wage) oriented if $\theta<(>) \frac{1}{2}$.

${ }^{16}$ From (37) and (42), this set of parameter values is given by the inequality:$$
\theta<\frac{\left(52-160 t+184 t^{2}-24 \sqrt{4-20 t+37 t^{2}-24 t^{3}+5 t^{4}}\right)}{2\left(5-32 t+44 t^{2}\right)}
$$ 


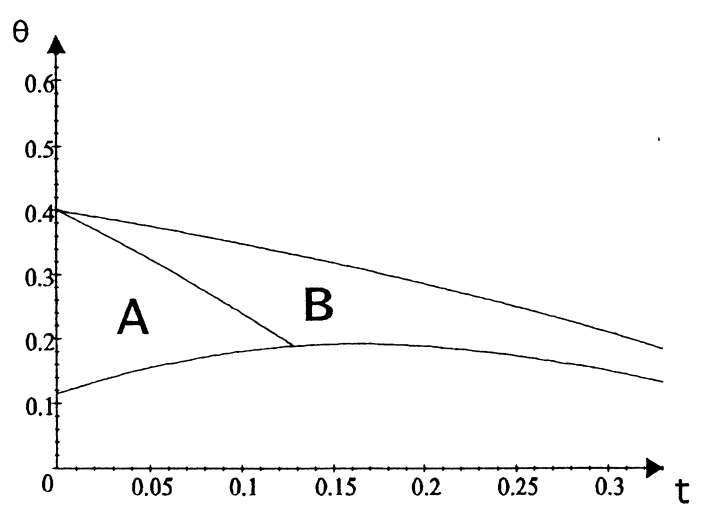

Fig. 2. Unionisation and welfare.

sufficiently low, there exists a set of parameter values for which unionisation could improve social welfare.

\section{Concluding remarks}

This paper deals with an example of the more general problem of collusion in markets where firms interact strategically not only with other firms, but also with other types of players, most notably labour unions. We have attempted to analyse the incentives for collusive behaviour in a repeated game version of the reciprocal dumping model. We have found that the scope for firm collusion is crucially dependent upon whether production costs are exogenously given or not. In the presence of labour unions, implying an endogenisation of production costs, we have shown that the non-cooperative trade equilibrium of the one-shot game Pareto-dominates the autarky equilibrium for every level of trade costs. In the absence of unions, however, the opposite is the case.

By having the advantage of being first-movers, the unions themselves have strong incentives to form a collusive agreement by raising the equilibrium wage above the Bertrand level of the one-shot game. And interestingly, when trade costs are sufficiently low the optimal collusive strategy implies intra-industry trade. Hence, the presence of labour unions will make trade more likely. This is the main result of the paper.

Given that union collusion is sustained as a subgame-perfect outcome of the supergame we have also analysed the effects of trade liberalisation on equilibrium wages. The most interesting result in this section of the paper is perhaps that within a certain interval of trade costs, trade liberalisation could result in a fall in wages, if union collusion is constrained by the possibility of firm collusion.

The welfare aspects of unionisation are also discussed, and we are able to show 
that if the unions are sufficiently employment oriented the presence of labour unions could possibly increase social welfare.

Due to the complex nature of a repeated two-stage game with four players, the results in the paper are naturally dependent on a number of assumptions, some being more crucial than others. Importantly, we have restricted the set of possible strategy combinations in the supergame by excluding solutions off the labour demand curves, implying that firms play their myopic best response in equilibrium. Solutions located off the labour demand curves would necessitate collusion between unions and firms, and in the context of a four-player model this would imply equilibria that are supported by both vertically and horizontally collusive agreements. Such equilibria would require very complex strategies, and in this paper we have chosen to disregard this subset of possible equilibria due to lack of feasibility. However, in a full analysis of collusive behaviour in a unionised international duopoly it would be interesting to characterise the complete set of possible equilibria. This is left for further work.

\section{Acknowledgements}

Valuable comments from Kjell Erik Lommerud, Steinar Vagstad and seminar participants at the University of Bergen are gratefully acknowledged.

\section{References}

Abreu, D., 1986. Extremal equilibria of oligopolistic supergames. Journal of Economic Theory 39, $191-225$.

Anderson, S.P., Donsimoni, M.-P., Gabszewicz, J.J., 1989. Is international trade profitable to oligopolistic industries? International Economic Review 30, 725-733.

Brander, J.A., 1981. Intra-industry trade in identical commodities. Journal of International Economics $11,1-14$.

Brander, J.A., Krugman, P.R., 1983. A reciprocal dumping model of international trade. Journal of International Economics 15, 313-321.

Brander, J.A., Spencer, B.J., 1988. Unionized oligopoly and international trade policy. Journal of International Economics 24, 217-234.

Dowrick, S.J., 1989. Union-oligopoly bargaining. Economic Journal 99, 1123-1142.

Driffill, J., van der Ploeg, F., 1993. Monopoly unions and the liberalisation of international trade. Economic Journal 103, 379-385.

Driffill, J., van der Ploeg, F., 1995. Trade liberalisation with imperfect competition in goods and labour markets. Scandinavian Journal of Economics 97, 223-243.

Espinosa, M.P., Rhee, C., 1989. Efficient wage bargaining as a repeated game. Quarterly Journal of Economics 104, 565-588.

Friedman, J., 1971. A non-cooperative equilibrium for supergames. Review of Economic Studies 38, $1-12$.

Fung, K.C., 1991. Collusive intra-industry trade. Canadian Journal of Economics 24, 391-404. 
Huizinga, H., 1993. International market integration and union bargaining. Scandinavian Journal of Economics 95, 249-255.

Lommerud, K.E., Sørgard, L., 2001. Trade liberalization and cartel stability. Review of International Economics 9, 343-355.

Mezzetti, C., Dinopoulos, E., 1991. Domestic unionization and import competition. Journal of International Economics 31, 79-100.

Naylor, R.A., 1998. International trade and economic integration when labour markets are generally unionised. European Economic Review 42, 1251-1267.

Naylor, R.A., 1999. Union wage strategies and international trade. Economic Journal 109, 102-125.

Pinto, B., 1986. Repeated games and the reciprocal dumping model of trade. Journal of International Economics 20, 357-366.

Sørensen, J.R., 1994. Market integration and imperfect competition in labor and product markets. Open Economic Review 5, 115-130. 